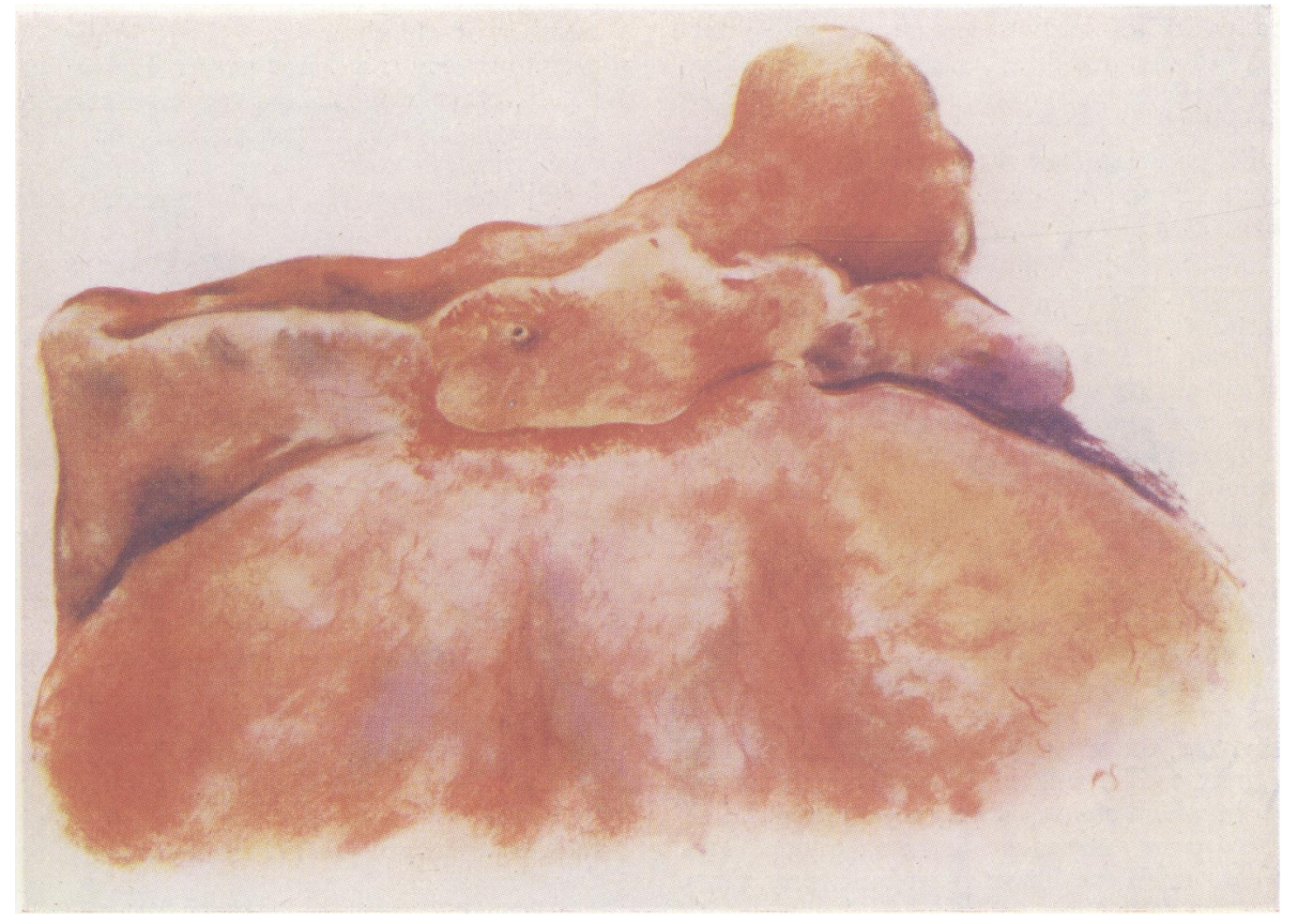

Fig. 7.-Painting showing sclerotic vessel end projecting from the base of an ulcer.

\title{
THE SURGICAL TREATMENT OF HAEMATEMESIS AND MELAENA
}

\author{
By Norman C. Tanner, F.R.C.S., and Andrew M. Desmond, F.R.C.S. \\ London
}

Just over sixty years ago, in 1887 , Mikulicz performed the first recorded successful operation for haematemesis. Ten years later he stated, 'it can never be prophesied with certainty in any individual case if haemorrhage is really of sufficient danger to justify surgical interference, so that one should always wait and see whether the bleeding will not be arrested by medical treatment ' (Hurst and Stewart, 1929). Thus commenced one of the major controversies of modern therapeutics.

It is not surprising that in those earlier days, when surgical intervention was attended with a high mortality, a purely conservative approach to the problem was favoured, particularly by Sir Arthur Hurst (1936) who produced figures to support his beliefs. Some physicians were im- pressed, however, by their autopsy findings, when it was not infrequently found that the patient had expired from continued bleeding from an easily accessible ulcer, and so in cases of persistent severe bleeding they called in a surgeon. Not unnaturally intervention at a late stage, when the patient's condition had deteriorated as a result of prolonged bleeding, was on the whole not very successful, though occasional dramatic results were obtained.

The realization of the risks associated with late intervention led to a movement, headed in this country by Sir G. Gordon-Taylor, which advocated early surgery in cases considered likely to continue bleeding, and this policy of 'selective surgical intervention' is the one which is most in favour and is most practised in this country today. 
The policy of early selective surgical intervention has a serious drawback, namely, that it is a matter of the greatest difficulty to decide which cases are likely to continue bleeding, and by the time the clinician has made up his mind, the surgical intervention is no longer early and carries all the risks of late surgery. Therefore Finsterer (1947) adopted a new approach to the problem. He suggested that all cases of chronic peptic ulcer which suffered a massive gastro-duodenal haemorrhage should be operated on at once, for they required surgical treatment quite apart from their bleeding, and surgery at the onset of the bleeding would be almost as safe as normal interval surgery and would also prevent further bleeding. He suggested that in cases in which it was not certain that the bleeding was due to chronic peptic ulcer, an expectant policy should be followed, but explorative laparotomy should be performed if the bleeding was repeated or persisted.

Briefly then, these are the different methods of dealing with the problem of gastro-duodenal haemorrhage, and we have to decide which method is the best today, under the particular circumstances in which the cases are encountered. The latter two points are to be borne in mind. The treatment which may have been best forty years ago may not be the best today, for in the meantime the relative risks of medical and surgical treatment have changed. The mortality of medical treatment has diminished because of the freer use of blood transfusion and the more liberal feeding and fluid replacement now advocated. The mortality of surgical treatment has diminished for the same reasons and also because of the greatly lowered operative mortalities for gastric surgery which have been experienced of late years. One must also consider the circumstances under which the cases are encountered and in particular the availability of an experienced gastric surgeon. These cases are not for the tyro for they sometimes present great operative difficulty in a patient too ill to withstand prolonged or crude surgery.

\section{The War of Statistics}

We know no better way to describe the sometimes unharmonious discussions which have taken place between the various protagonists of the different methods. Incredibly high and low mortalities have been presented from different clinics in support of one method or another. It is most obvious that the different workers were describing different types of cases. For example, the one might describe the results in a hospital where cases of the mildest degree were accepted, another a hospital where only the most severe were admitted. Some groups of cases almost exclude elderly persons, others include an abnormally high number of elderly cases. Some groups include private cases or a large percentage of duodenal ulcers, other groups include a high percentage of the more lethal bleeding gastric ulcers. Therefore comparison between the general mortality figures for different types of clinic is extremely fallacious.

Comparison of mortalities between one surgeon operating for haematemesis and another is also fallacious. A high operative mortality is consistent with life-saving surgery if the surgeon is operating only on those who are almost certain to die, while a low operative mortality may be excessive if the surgeon is operating only on the ' good risk' cases. Some selection may occur also if the surgeon is only asked to see cases in which it is considered that surgery will be successful.

To quote from Avery Jones' Goulstonian lectures, 'a high mortality for delayed operation is not necessarily an argument against it if by waiting one can distinguish a group of patients who carry an exceptionally high mortality with medical treatment.'

Therefore in an endeavour to elucidate this problem during the last ten years one of us (N.C.T.) has taken the opportunity of treating large numbers of cases of gastro-duodenal haemorrhage by all of these methods, and the basis of this report is an analysis of the clinical materiale studied. It must be stated that the hospital concerned is a large municipal one in South-West London. The average age of patients treated is high, more than a third are over sixty. The incidence of gastric ulceration is high in the district served, there being only a slight predominance of duodenal ulcers. All cases admitted to the hospital have been treated in the same way and under the main direction of one clinician directing a keen and interested team of colleagues, house officers and nursing staff.

\section{The Causes of Gastro-Duodenal Bleeding}

This table shows the total clinical material studied and includes all cases of gastro-duodenal haemorrhage from January I94I to September I949.

It will be seen that peptic ulcer and gastritis together account for the bleeding in about 85 per cent. of the cases. In considering the various causes of bleeding it is convenient and practical to consider the peptic ulcer-gastritis group together, for both present as a rule with dyspepsia, some are possibly of similar aetiology, acute erosions or ulcers may be associated with the gastritis and they present a similar problem in treatment. Among the uncertain group are no doubt some acute ulcers or gastritic lesions which are healed by the time investigation is possible, or are missed at the time of investigation. They may also include 
TABLE I

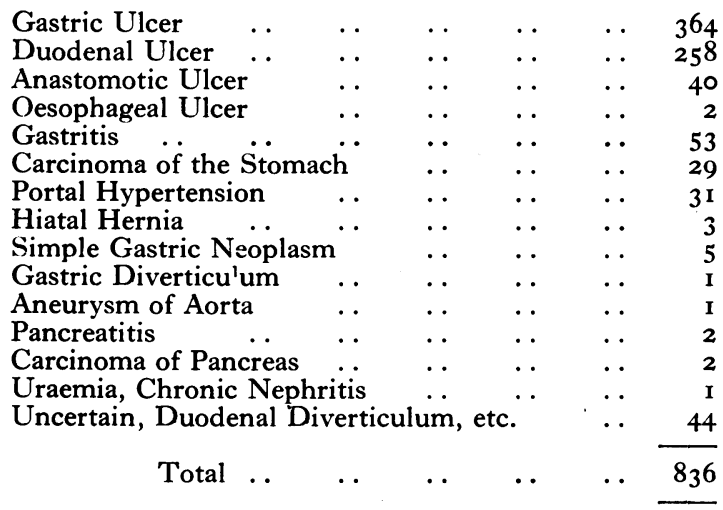

such conditions as toxic gastritis, gastrostaxis, acute oesophageal ulcer, etc.

Before proceeding to discuss the peptic ulcergastritis group a few notes may be made on the other causes of gastro-duodenal bleeding.

\section{Carcinoma of the Stomach}

This was the cause of bleeding in 29 cases. As stated previously (Tanner, 1949), massive bleeding from a carcinoma of stomach is by no means a sign of inoperability, for of these 29,14 were eventually resected and discharged from hospital well, four requiring a total gastrectomy.

Seven of the cases required urgent surgery, and of these immediate partial gastrectomy was done in two cases with recovery in both, and abdominal total gastrectomy in one, which proved fatal. One of the cases was interesting, as a severe haemorrhage from an inoperable carcinoma was sufficient to rupture the stomach, the tear starting at the edge of the growth. The patient was a man, aged $5^{\circ}$, who had settled down after a haematemesis and was awaiting surgical exploration. One morning he had a haematemesis followed by abdominal pain and shock. At laparotomy a tear was found extending from a carcinoma of the cardia into the anterior stomach wall, and the peritoneal cavity was full of blood clot. The growth was irremovable, and he had hepatic metastases.

\section{Haemorrhage from Simple Gastric Neoplasms}

These tumours were fibroleiomyomata in three cases; there was one case in which an islet of ectopic pancreas on the anterior wall of the duodenum was ulcerated, and the others were adenomatous polyps. The tendency of the fibroleiomyomata of the stomach to ulcerate, causing either massive or slow continued bleeding is notorious. None of these cases required emergency surgery, and all were dealt with surgically

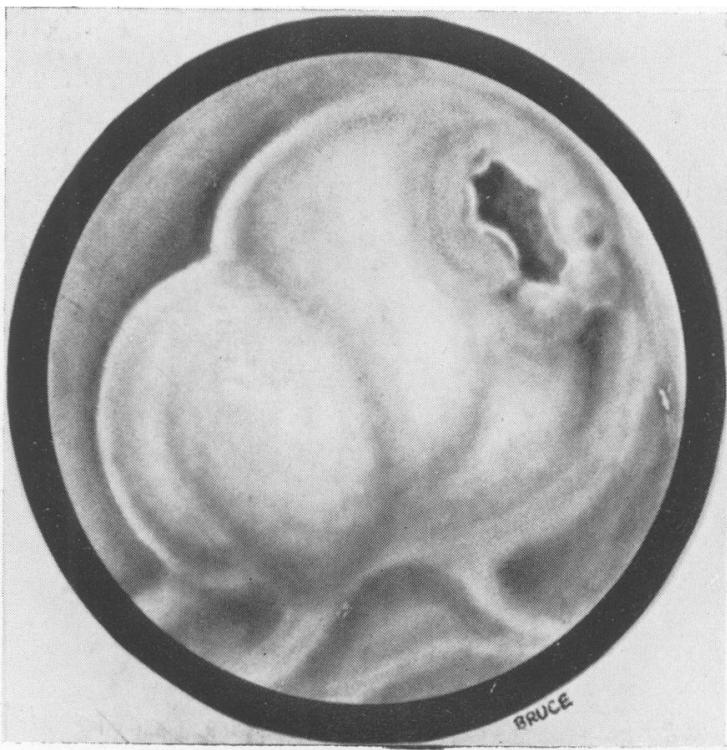

FIG. I.-Gastroscopic view of ulcerating simple gastric neoplasm.

on the usual lines at a later date. The smaller tumours may be missed or mistaken for blood clot at laparotomy unless the surgeon is wary. These tumours should always be visualized and mapped out gastroscopically before embarking on resection or the smaller neoplasms may be overlooked. They are, of course, readily seen at gastroscopy (Fig. I).

\section{Hiatal Hernia}

Herniation through the diaphragmatic hiatus with or without a short oesophagus may be the only finding in some cases of haematemesis or melaena. In such cases one should make careful gastroscopic and oesophagoscopic examination to exclude the presence of oesophageal or gastric ulceration. Needless to say care should be taken in the passage of the gastroscope, but if good views are obtained one can sometimes distinguish an infra- and a supra-diaphragmatic part of the stomach, each with a separate mucus lake and separated by an extragastric constriction which moves with respiration-the margin of the diaphragmatic hiatus.

Some of these haemorrhages are caused by oesophageal regurgitation and peptic oesophagitis, or gastritis, or congestion of the fundus of the stomach when temporarily incarcerated in the thorax. In none of the three cases in this series was urgent surgery required.

\section{Pancreatic Lesions}

It is not well known that acute, or subacute pancreatitis, or pancreatic carcinoma may cause 


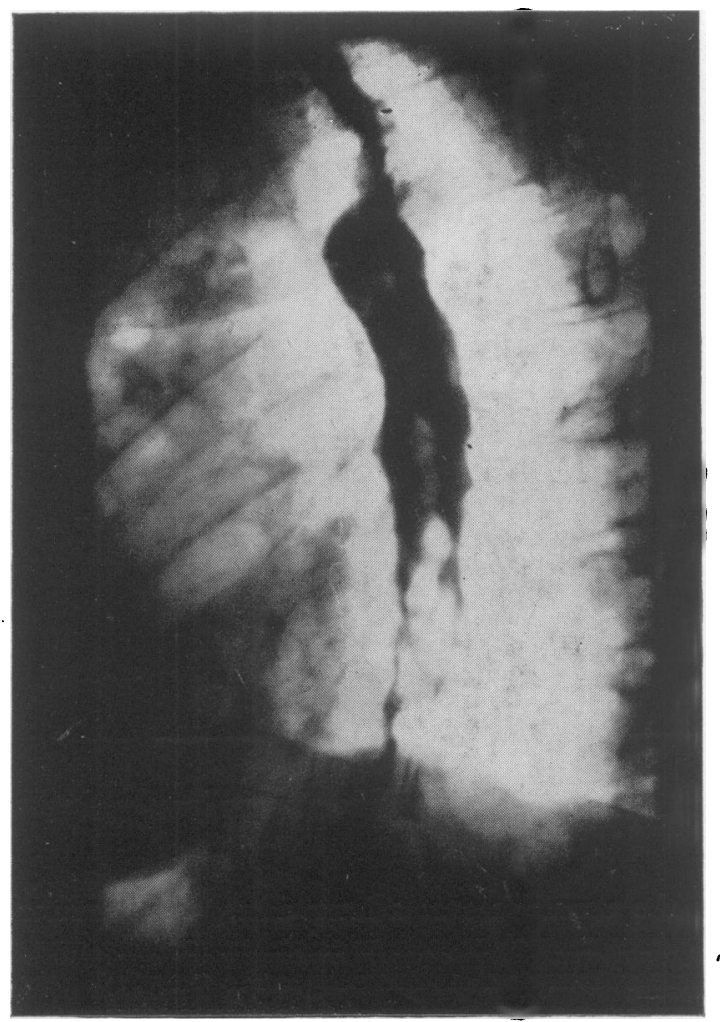

FIG. 2.-X-ray of barium swallow after haematemesis, showing oesophageal varices.

severe haematemesis, but in this series two cases of each were encountered. The carcinoma caused bleeding in each case by ulceration of the growth into the duodenum. Of the two pancreatitis cases one was fatal and at autopsy the necrotic pancreas was found to be inseparably adherent to the posterior wall of the pyloric antrum, which was extremely congested but not ulcerated.

\section{Portal Hypertension}

There were $3 \mathrm{I}$ cases in which the bleeding was due to portal hypertension, of whom 18 died and I3 survived. In all these cases the bleeding appeared to be: due to acute erosions overlying oesophageal varices (Fig. 2). One of us (N.C.T.) has, however, on two occasions performed gastrectomy for recurrent haematemesis in cases of duodenal ulcer associated with cirrhosis of the liver, and this possible though unusual combination should not be forgotten.

In some of the cases, portal hypertension may be clinically obvious, but in the majority the differential diagnosis during the bleeding phase may be difficult. If clinically obvious, the introduction of a special Miller Abbott tube with the bag removed from the end and re-inserted some 8 to 10 in. higher up (Fig. 3) may be useful (Rowntree et al., 1947). If this is correctly placed (Fig. 4) it will impede the connection between the hypertensive portal and the systemic azygos veins.

In a certain number of cases this condition was encountered at emergency operation for haematemesis, and the results of the various operative procedures are given in Table 2.

TABLE 2

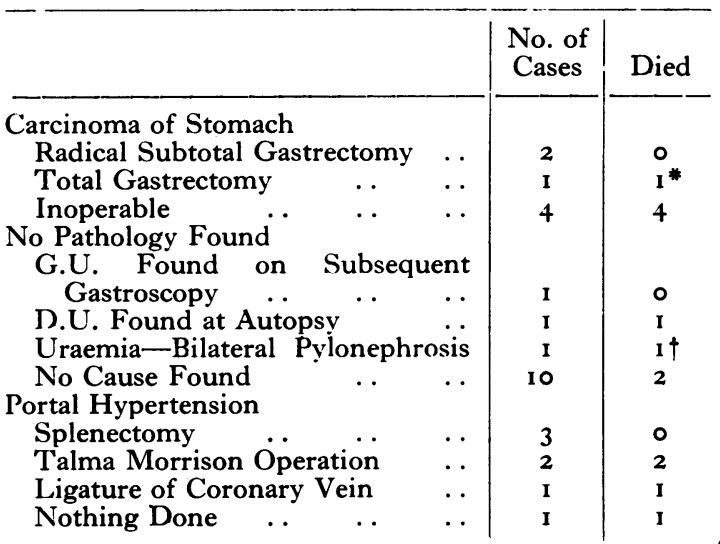

* Peritonitis.

$\uparrow$ Bleeding controlled.

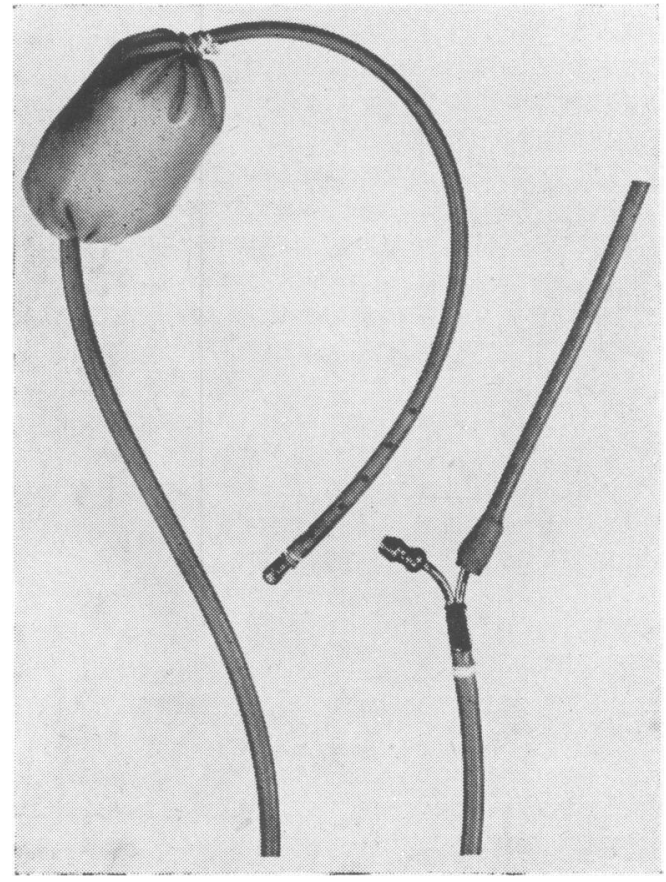

FIG. 3.-Tne Miller-Abbott tube with the bag removed and reinserted further up the tube.

(Reproduced by courtesy of the Medical Press) 


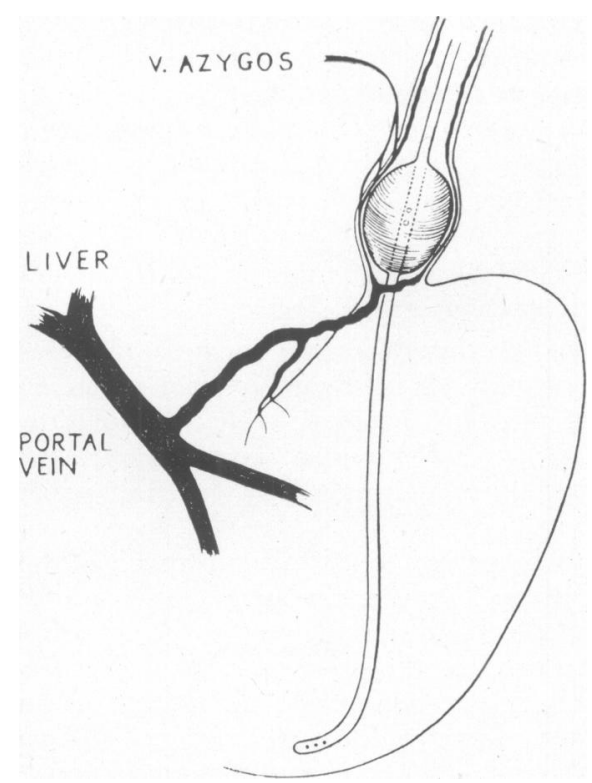

FIG. 4.-The bag inflated in the lower oesophagus, feeding and aspiration tube in position. The flow from the portal to azygos veins is obstructed.

(Reproduced by courtesy of the Medical Press)

Although these cases often present a very urgent immediate problem, the problem of preventing recurrence is no less important, for we have found 100 per cent. recurrence of bleeding at variable times after the initial bleeding, unless some drastic interval surgery was undertaken. We have not had good results from oesophagoscopic injection of the varices, and the choice of treatment lies between some form of porto-systemic venous anastomosis and surgical interruption of the blood flow from portal to azygos veins. One of the authors has practised subcardiac gastric transection with some success on a short-term follow-up (Tanner, 1949).

\section{Gastric and Duodenal Diverticula}

We have doubts as to how often these conditions cause haematemesis. Although gastric diverticulum was blamed in one case in the series, we should add that we have not proved any case of haemorrhage to be indisputably due to a diverticulum.

\section{Peptic Ulcer and Gastritis}

This group is the one which is usually selected for comparison. As mentioned, there may be some cases of acute peptic ulceration included in the gastritis group, and there are severe cases of gastritis in the peptic ulcer group. It is the influence of surgery for haemorrhage in this group which we desire to elucidate.

\section{Factors influencing Mortality from Gastro- Duodenal Bleeding}

It is important to appreciate certain factors which influence the mortality before we can assess our results; these factors are therefore briefly reviewed.

I. The severity of the haemorrhage. The initial haemorrhage may be sufficient to cause considerable collapse, or it may cause little more than momentary faintness. The former or 'grave' type of bleeding is much more dangerous and, in fact, it is at times difficult to find signs of life. In this condition of collapse irreversible changes may occur in the tissues and permanent cerebral damage or amaurosis may occur. The danger may be even greater if the patient is already anaemic from chronic slight bleeding.

Not unnaturally it is in the severe cases in which the mortality is greater as shown by Aitken (1934), who found a mortality of I I per cent. in his series of 255 cases, but it was 43 per cent. in the severe cases. Bulmer (1932) and Bennett, Dow and Wright (I942) described similar results.

2. Repeated or continuing haemorrhage. Chiesman (1932) found that a single haemorrhage rarely caused death, a finding with which we concur, but repeated haemorrhages, particularly if severe, are associated with an ever-increasing mortality. This is illustrated in Table 3 .

TABLE 3

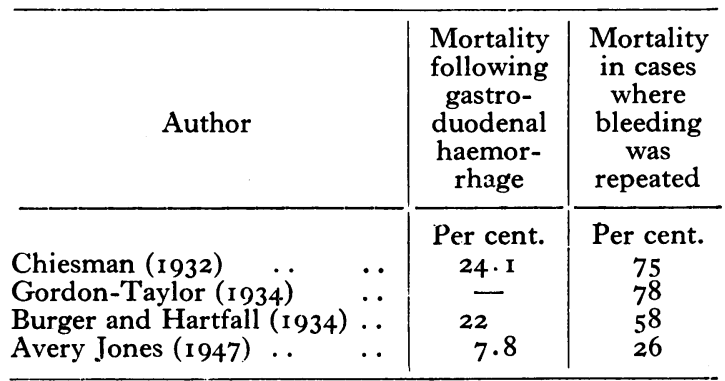

3. Age. Almost every author who has studied this subject has described a great increase in mortality from bleeding peptic ulcer with advancing years. For example, Avery Jones (1947) had a total mortality in 6 I $_{5}$ bleeding peptic ulcers of 7.8 per cent. Under 45 the mortality was 2 per cent., then it rose to 6 per cent. between the ages of 45 and 59, 12 per cent. between 60 and 69, and finally 2 I per cent. over 70 .

The main causes of this rise in mortality with age are three:-

(a) The increased gastric to duodenal ulcer ratio with advancing years. This is substantiated by Fig. 5, which is a graph made from an analysis of $I, 300$ consecutive cases of ulcer treated in this 


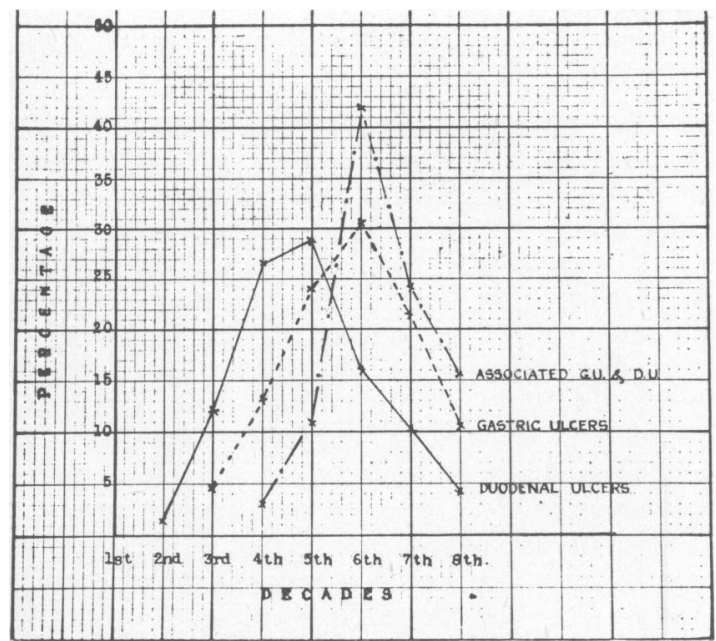

FIG. 5.-Graph showing the age incidence of gastric and duodenal ulcer. An analysis of 1,300 cases.

clinic. The significance of this altered ratio is, of course, that haemorrhage from gastric ulcer carries a higher mortality than that from duodenal ulcer (Avery Jones, 1947).

(b) The increasing incidence of arteriosclerosis in older patients, which renders the bleeding vessel less able to contract.

(c) The increased incidence of cardiac, renal, cerebral and other lesions in older patients, as well as the lessening resilience and resistance to infection with advancing years.

The availability of skilled medical and surgical assistance needs little emphasis. While many of the cases would recover spontaneously without special medical care, there is no doubt that the availability in particular of blood transfusion, chemotherapy and occasionally surgical aid will greatly influence the mortality.

We do not intend to discuss the relative merits of early or late transfusion, but the patient must not be allowed to become so anaemic that a further haemorrhage is likely to prove rapidly fatal, and it must be borne in mind that the aged are less able to withstand prolonged anaemia than the young.
4. The time when surgical interference is undertaken has an undoubted effect on the operative mortality as shown by Table 4 .

With these points in mind we now go on to describe some of the details of our investigations and their results.

\section{The Investigation}

\section{Elimination of Variable Factors}

As stated, the object was to study the effects of different methods of treatment on a series of cases treated at one hospital, thus eliminating the variables which render comparison between different types of hospitals in different regions so valueless.

The cases were treated in two medical and two surgical wards, under the same clinician and with keen medical and nursing teams. A list of routine instructions on the treatment of cases, feeding,. morphinization, indications for blood transfusion, etc., were displayed in each ward and followed as far as possible. These routine instructions have been previously published (Tanner, I949).

This was about as far as it was possible to go in the standardization of the basic treatment. Not unnaturally, in ten years' investigation of this sort variables crept in. There was some slight variatiof in the ages of cases admitted, the war led to diminution of staff, bombing led to sporadic in creases of gastro-duodenal bleeding, and the introduction of newer chemotherapeutic agents diminished mortalities from infection.

Variation in the standard of surgical aid was largely eliminated, as all the surgery until 1946 was done by the senior author and later by both of us. One cannot over-estimate the importance of the amount of experience in gastro-duodenal surgery required before undertaking these cases. Ivor Lewis has suggested that no one with a mortality of over 5 per cent. in his ' cold' gastrectomy for ulcer cases should deal with them (1946). During the last war, because his chief assistant was away, Finsterer (1947) dealt personally with every haematemesis requiring surgical treatment, even at night.

In our clinic we now have an increasing number of highly trained gastro-enterological surgeons,

TABLE 4

Early and Late Operation for Gastro-Duodenal Haemorrhage

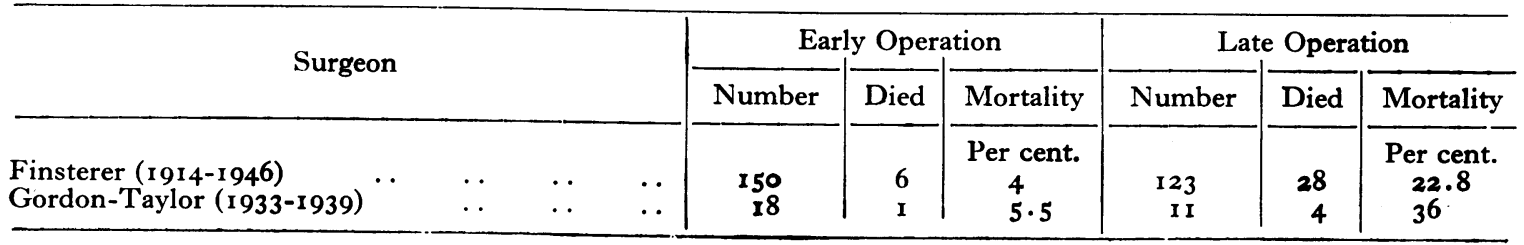


and so occasional operations for haemorrhage are very successfully carried out by them.

\section{Variations Purposely Made in Treatment}

In the first period from June, I94I, to June, I943, conservative treatment was adopted, operation being reserved for a few late cases. In the next period from December, 1943, to June, 1944, operation was more readily undertaken, was early and the operation was always a gastrectomy. This series was not carried on long because the war was entering a difficult phase, staff was short and a particularly severe group of haemorrhages was treated. From June, I944, to December, 1947, was a period of selective surgical intervention. About the same number of cases were operated on but the operation was as simple as possible, though often gastrectomy, and was earlier than in the first period.

The present period has lasted since January I, 1948. During this time we have followed the dictates of Finsterer (1947). These, as we understand them, are:-

I. If a patient is admitted with a massive gastroduodenal haemorrhage, and is known to be suffering from a chronic peptic ulcer, immediate surgery is undertaken.

2. If a patient is admitted with a massive gastroduodenal haemorrhage and has no history of chronic peptic ulceration, he is treated conservatively, but a repetition of bleeding or persistent bleeding is an indication for surgical exploration.

We have followed these rulings completely with the following three provisos:-

I. On rare occasions when either of the two surgeons dealing with these cases were not available, expectant treatment was continued rather than have the case dealt with by an inexperienced surgeon.

2. A good clinical history of chronic ulceration was accepted as evidence of chronic ulceration.

3. In a few cases in young persons under 25 suffering from haemorrhage from a chronic duodenal ulcer, including patients aged 14,16 and 17. conservative treatment was adopted in the acute phase of bleeding.

During the last phase one small variation was made in the surgical technique in dealing with duodenal ulcer. During 1948, from January I to December 31, bleeding posterior duodenal ulcer was treated by duodenotomy, ligature of the bleeding point and gastro-jejunostomy. In 1949 most such cases have been treated by gastrectomy.

A resume of our results is as follows (these are incidents of haemorrhage, about 30 cases being admitted on more than one occasion):-

In considering these results the age of the relative groups should be borne in mind. The average age of the whole series is higher than any yet recorded, and it will be seen that in the last group no less than 42 per cent. of the cases were over 60 years of age, in spite of which the mortality was the lowest in the series. It is also a most valuable exercise to study the fatalities. A possible criticism of surgery is that young patients might be lost who would have rycovered with conservative treatment. Consideration of the average age of the patients who died shows, however, that the mortality was in the older groups.

It may also be said that perhaps the writers were more interested in surgery than in medical treatment. One can only say that every case was treated as enthusiastically in the medical as in the surgical wards. The writers are, in fact, interested in medical treatment, for one of us (N.C.T.) has had charge of every dyspepsia, functional and organic, which has entered the hospital since 1940.

One cannot over-estimate the importance of enthusiasm in dealing with these cases, and the mortality is noticeably improved if a trained and enthusiastic ward sister is in charge. Every mortality, medical and surgical, should be regarded as a tragedy and lead to careful consideration of the circumstances which may have led to failure.

TABle 5

Peptic Ulcer and Gastritis Groups (Incidents of Bleeding)

\begin{tabular}{|c|c|c|c|c|c|}
\hline & $\begin{array}{l}\text { No. of } \\
\text { Cases }\end{array}$ & $\begin{array}{c}\text { Over } \\
60\end{array}$ & $\begin{array}{c}\text { Operated } \\
\text { On }\end{array}$ & $\begin{array}{c}\text { Overall } \\
\text { Mortality }\end{array}$ & $\begin{array}{c}\text { Average } \\
\text { Age of } \\
\text { Patients } \\
\text { who Died }\end{array}$ \\
\hline 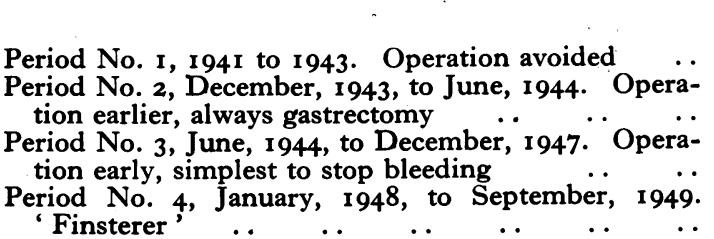 & $\begin{array}{r}193 \\
60 \\
312 \\
183\end{array}$ & $\begin{array}{c}\text { Per cent. } \\
33 \\
33 \\
35 \\
42\end{array}$ & $\begin{array}{c}\text { Per cent. } \\
5 \\
15 \\
11 \\
60\end{array}$ & $\begin{array}{c}\text { Per cent. } \\
\text { 10 } \\
20 \\
\text { I I } \\
7\end{array}$ & $\begin{array}{l}62 \\
62 \\
65 \\
16\end{array}$ \\
\hline
\end{tabular}




\section{Results in the Whole Series}

A statement of the results in the whole series may be of interest.

\section{Mortality I 94 I to 1949}

(I) Whole Series

\begin{tabular}{|c|c|c|c|c|c|}
\hline Total cases & .. & .. & . & . & 836 \\
\hline Deaths .. & . & . & . & . & 103 \\
\hline Mortality & . & . & . & . & .. $\quad 12 \%$ \\
\hline No. over age of 60 & & $\cdots$ & .. & . & $\cdots \quad \begin{array}{r}294 \\
(41 \%)\end{array}$ \\
\hline
\end{tabular}

(2) Peptic Ulcer and Gastritis Group

\begin{tabular}{|c|c|c|c|c|}
\hline 7 otal cases & $\cdots$ & $\cdots$ & $\cdots$ & \\
\hline Deaths . & $\ldots$ & .. & $\ldots$ & 78 \\
\hline Mortality & . & . & $\ldots$ & .. $\quad 11 \%$ \\
\hline No. over age of 60 & . & $\cdots$ & . & $\cdots \quad \begin{array}{c}274 \\
(38 \%)\end{array}$ \\
\hline
\end{tabular}

Apart from the high average age of this series the high incidence of associated disease must be borne in mind. Of those who died, three had carcinoma in other organs, four had tabes dorsalis, two had paralysis agitans and four had old cerebrovascular lesions. Other complicating factors in the series were haemophilia, prostatic obstruction, prostatic carcinoma, ulcerative colitis, pancreatitis, transfusion jaundice, spinal tuberculosis, aortic aneurysm, pulmonary fibrosis, severe myxoedema, tetany, acute glaucoma, severe burns and a fractured femur. Nineteen were over 75 years of age.

\section{Clinical Evidence of Continuing Gastro- Duodenal Haemorrhage}

In considering surgical intervention it is most important to decide whether haemorrhage is continuing or repeated.

Fresh haematemesis, or fresh copious melaena, particularly if associated with collapse is an obvious sign of persisting haemorrhage. A rising pulse rate or falling or persistently low blood pressure and haemoglobin percentage are suggestive of continued bleeding if other causes can be excluded. In all acute haemorrhages the haemoglobin percentage will be maintained at normal for a few hours and only as plasma volume is restored will the level fall. Furthermore, shock may be responsible for considerable haemoconcentration. Thus haemoglobin estimations must be discounted for the first few hours after gastro-duodenal haemorrhage; also in the early stages a falling haemoglobin level is of little significance. Persistent turbulent peristalsis heard on abdominal auscultation apart from recent taking of fluid or food is suggestive of continuing haemorrhage, and its absence of cessation of haemorrhage (GordonTaylor, 1937).

\section{Estimation of Blood Volume}

We have not used this estimation as a clinical aid, but the work of Bennett et al. (1938), suggests that such estimations can be of the greatest value. As a simpler method of determining blood volume changes we have recently been using the copper sulphate falling drop method (Costello, 1949), but our impression is that it is less accurate than the haematocrit.

\section{Surgical Technique in the Treatment of Gastro-Duodenal Haemorrhage}

\section{Preparation for Operation}

The patient is resuscitated as expeditiously as possible and as soon as the decision to operate has been made, blood transfusion is increased in rate to 60 to 70 drops per minute. In severe cases two transfusions may be set up at the same time. When the pulse rate is steady, the blood pressure restored, preferably with the systolic blood pressure I IO $\mathrm{mm}$. Hg. or over, he is taken to the operating theatre in bed.

Three points must be strongly emphasized:-

I. Once active and vigorous resuscitative measures have been instituted, the patient's condition may improve so dramatically that one may be tempted to postpone operation. This would bee ill advised as the rapid increase in blood pressure and blood volume will make a further haemorrhage most probable.

2. Resuscitation must not be too vigorous and active, as a further haemorrhage may be precipitated before the patient is on the operating table.

3. It is essential that the surgeon be close at hand and the operating theatre in full readiness in case a further haemorrhage should occur. On several occasions we have known patients to suffer collapse and haemorrhage in transit to the operating room.

If facilities permit, it is better to carry out the final resuscitation and skin preparation in the anaesthetizing room of the theatre.

An oesophageal tube is passed gently and the stomach aspirated as far as possible. It is then left in situ during and after the operation. We have found that a Ryle's tube blocks too easily to be efficient, and so prefer an oesophageal tube with a somewhat larger bor 3 .

Blood transfusion is continued throughout the operation, the rate being dependent upon the patient's condition. A trained nurse or medical officer should be made responsible for this and it should occupy his constant attention, as the necessity for very rapid blood replacement may arise suddenly. Freeing the ulcer from an eroded splenic, hepatic or gastro-duodenal artery or dis- 
turbing a clot over the vessel may precipitate a catastrophic haemorrhage and a grave emergency. Two assistants are essential as at any time digital compression of a bleeding point may be required. Whilst over-dosage with morphia or its derivatives is dangerous and productive of post-operative chest complications, judicious medication with omnopon gives peace of mind to the patient.

\section{Anaesthesia}

Finsterer advocates local anaesthesia, with perhaps a little ether in younger patients. However, with modern methods, the emphasis on this point has declined in the reports of other surgeons.

Throughout this series local anaesthesia alone has been used. We consider that the anoxia, incipient uraemia and poor powers of resistance of the patient are contra-indications to any form of general or spinal anaesthesia. The method used has been an abdominal field block by means of infiltration of all the layers of the abdominal wall just medial to the costal margin, as far down as the iliac crest (Fig. 6), combined with anterior splanchnic anaesthesia (Braun), with $\mathrm{I}: 2,000$ amethocaine and $\mathrm{I}: 400,000$ adrenaline hydrochloride, using a total of $400 \mathrm{cc}$. of solution. Omnopon, gr. $\frac{1}{3}$. is given intravenously at the outset, and gr. $\frac{1}{6}$ subsequently if necessary. Sometimes the anaesthetist has induced light anaesthesia with cyclopropane or pentothal when the patient has been uncooperative or restless, but only on a few occasions has this been necessary. If it is suspected that there are dense adhesions between the stomach and liver, and of the lesser sac of peritoneum, we sometimes use a posterior splanchnic (Kappis) anaesthesia before laparotomy. In about 15 to 20 per cent. of the cases the splanchnic anaesthesia has been incomplete (it may be tested by observing the reaction on squeezing the right gastro-epiploic artery with a forceps), in which case some anaesthetic solution is injected round the main vessels (right and left gastric, right and left gastro-epiploic arteries).

\section{Operative Procedure}

The incision. We prefer a midline incision as this is the most rapid and bloodless entry to the upper abdomen. If, however, a difficult and deep duodenal dissection is required, we have not hesitated to make a transverse extension of the incision to the right, or have even used a transverse incision for preference. A very vascular entry gives rise to suspicion of portal hypertension.

Identification of the lesion. After opening the peritoneum the presence of dark altered blood in the small intestine or colon is looked for. The stomach and duodenum are carefully inspected as

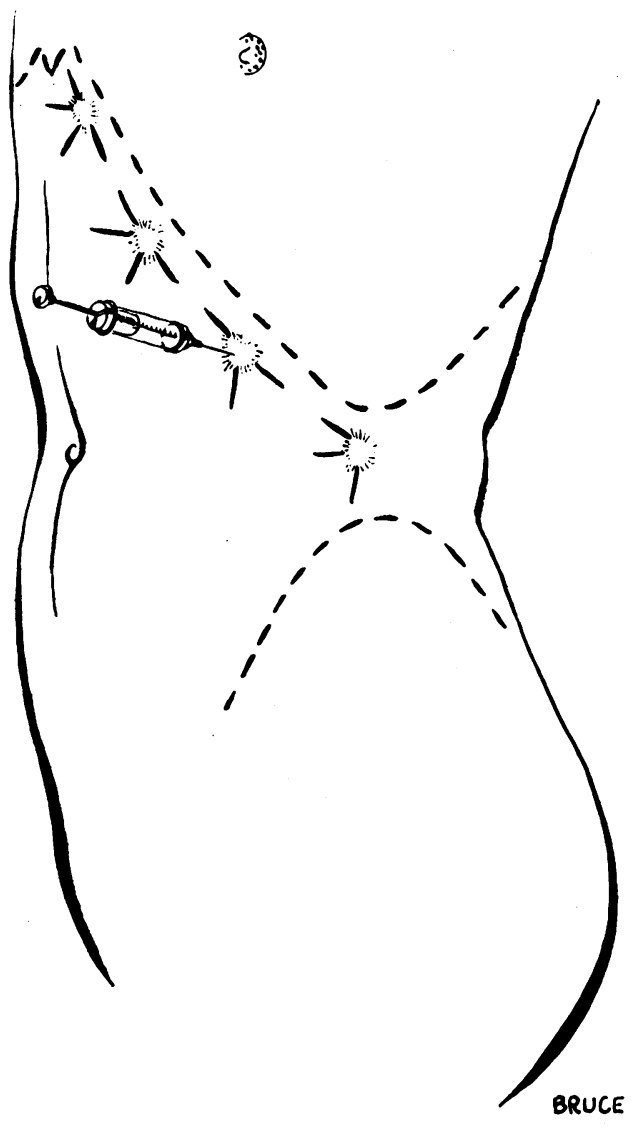

FIG. 6.-The sites of injection of anaesthetic solution for the field block

well as palpated on both anterior and posterior surfaces, the gastro-colic and/or gastro-hepatic omenta being freely opened if required and the stomach rotated. Particular attention is paid to the descending part of the duodenum as an ulcer in this area penetrating the pancreas was in one case overlooked with fatal result. The liver is inspected for evidence of cirrhosis and the spleen for enlargement, peri-splenitis or hardening. The pancreas is examined for evidence of pancreatitis or carcinoma. A systematic examination of the rest of the abdominal viscera is made to exclude an unsuspected carcinoma or other lesion.

In most cases a causative lesion will be found, but in a few cases it eludes detection. In such cases a gastro-duodenotomy, a longitudinal incision passing through the pylorus and adjacent stomach and duodenum, is justified. The mucosa itself should be palpated and most of the stomach and proximal duodenum can be examined in this way. On three occasions the palpating finger has felt a bristle-like projection, this being an athero- 


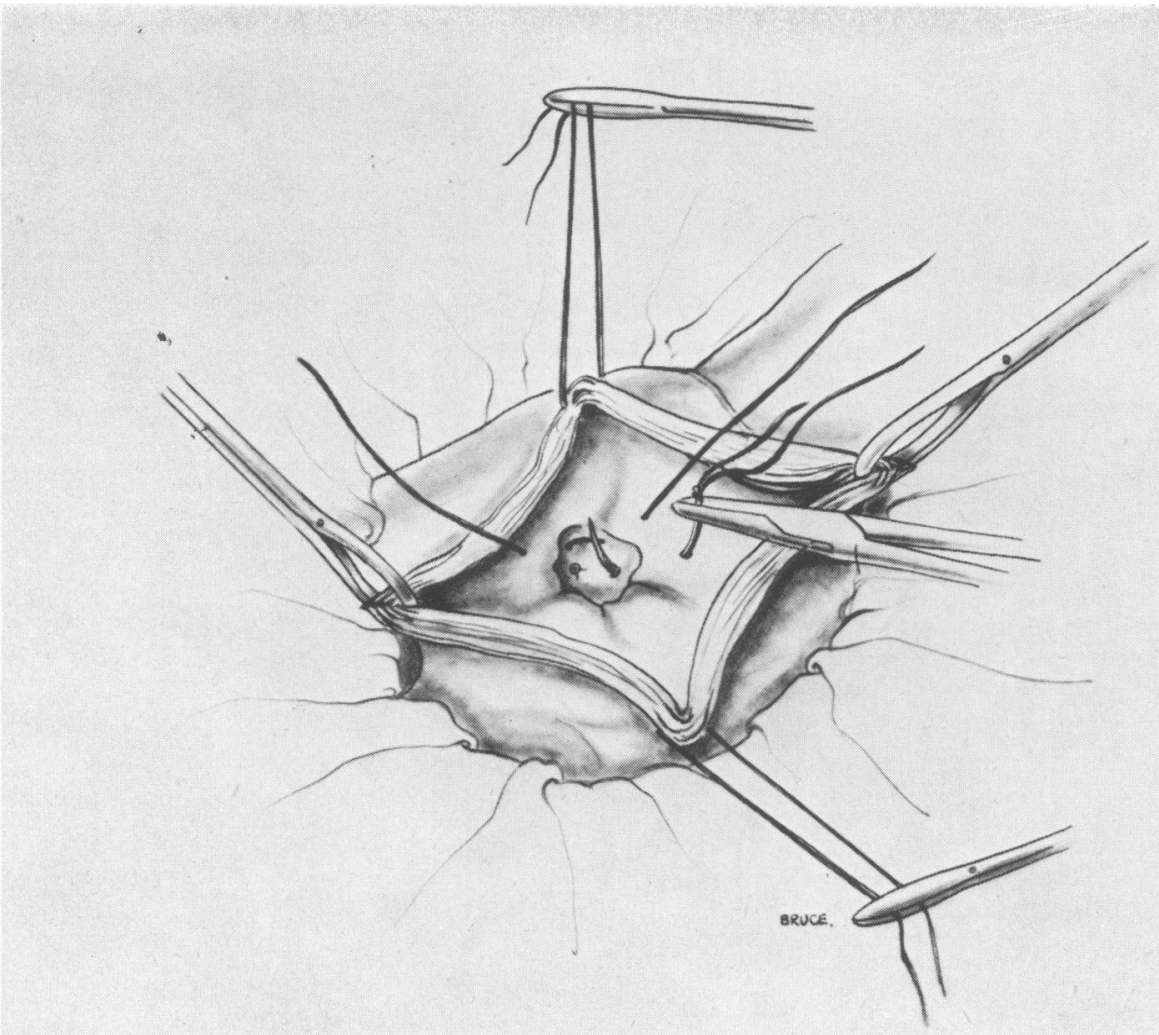

Fig. 8.-Gastro-duodenotomy. Deep sutures are placed to draw ulcer edges firmly together.

sclerotic vessel (Fig. 7) end projecting out of a small but fibrotic ulcer, which itself was impalpable. Inspection of the lumen is best made by means of an illuminated retractor or a headlight and two broad flat retractors. In spite of this routine the lesions may still escape detection and in one such case we discovered a small gastric ulcer at a subsequent gastroscopy. It has long been the opinion of the senior author that a successful gastroscopy far supersedes exploratory laparotomy as a means of detecting small gastric ulcers.

\section{Control of Haemorrhage}

\section{(a) In Ulcer Cases}

Whatever method is used, if an ulcer is present, an attack must be made on the bleeding point. Such indirect methods as gastro-jejunostomy alone, jejunostomy, tamponage, vasoligation from outside the stomach, etc., are often ineffective and frequently followed by further haemorrhages.

This broad question then arises. Should one perform the smallest possible operation which will ensure arrest of bleeding for a short time and perhaps perform definitive surgery later, or should one undertake immediate gastrectomy?

A list of the 'smaller' procedures we have performed are as follows :-

\section{For Gastric Ulcer}

I. Local or sleeve resection.

2. Gastrotomy and suture of the ulcer bed with silk mattress sutures.

3. Ligature of the vessels entering an ulcer crater from outside the stomach.

4. Separation of a penetrating ulcer from the penetrated organ (e.g. liver and/or pancreas), trimming of the ulcer edges and closure of the resulting opening in the stomach. Great care must be taken not to leave a bleeding bessel unsutured in the ulcer edge.

\section{For Duodenal Ulcer}

Duodenotomy (exposure of the ulcer and its obliteration by inserting deep interrupted silk sutures from one edge to the other) (Fig. 8), followed by repair of the duodenotomy and then gastro-jejunostomy. 


\section{For Gastro-fejunal Ulcer}

Gastrotomy and closure of the ulcer base with interrupted silk sutures.

In the earlier series a number of these minor procedures were used, particularly if the patients were very ill. With the possible exception of local and sleeve resection of the ulcer they are not so reliable in causing cessation of haemorrhage. For example, we had three recurrent haemorrhages after duodenotomy and gastro-jejunostomy, one of which was fatal and another required a further operation. In the majority of gastric ulcers we have found gastrectomy the easiest and the most certain way of stopping the bleeding. Since January, 1949, we have treated every duodenal ulcer the same way with better results than we obtained from duodenotomy.

Nevertheless there is still a place for the less drastic procedures in the feeble or ' late' case and in the case with great technical difficulty. If a surgeon who has not had an extensive experience of gastric surgery is called upon to deal with such emergencies then he would be wise to consider the less drastic operations.

\section{(b) In Cases Where No Ulcer was Found}

In a certain number of cases no ulcer was discovered at laparotomy. Of late we have reduced this number by making a gastroscopic examination in doubtful cases prior to laparotomy, and it is surprising how often excellent views of the stomach are obtained. In no case has the examination precipitated fresh bleeding. Table 2 (p. 354) briefly summarizes our findings and the mortality in those cases operated on as an emergency in which no ulcer was found.

\section{Post-operative Care}

It is most important to attain and maintain a haemoglobin level of at least 70 per cent. by blood transfusion and adequate iron therapy. We find that these cases, especially if left with a persistent anaemia, are more liable to post-operative chest complications and wound sepsis than the 'cold' gastric cases. Penicillin is therefore given prophylactically. Post-operative vitamin deficiency is remedied by large doses of vitamins $B, C$ and $\mathrm{K}$, and a high protein diet is instituted as early as possible. Graded limb exercises, postural lung drainage and deep breathing are carried out at routine intervals after the first 12 hours, but full bed rest is continued until the blood count is satisfactory.

Post-operative pyrexia up to $101^{\circ}$ to $102^{\circ} \mathrm{F}$. is common, and a dramatic fall to normal usually occurs after the altered blood has been evacuated on the third or fourth day by means of an enema.

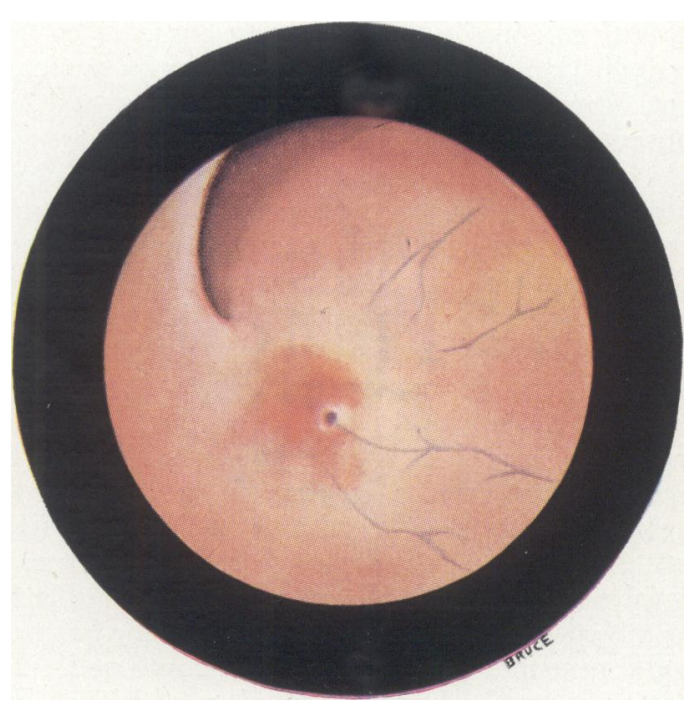

FIG. 9.-Atrophic gastritis, but with a minute ulcer overlying a submucosal vessel (gastroscopic view). (Reproduced by courtesy of the Medical Press)

The improvement in the patient's feeling of wellbeing after this event is most dramatic. Pauchet said that these patients suffered from an over $z$ dose of 'black pudding,' and to evacuate this he was wont to perform a caecostomy. We alsơ notice that these patients require more time before returning to full employment than after nonurgent surgery.

Brief notes on some of the other points which arise in the surgical treatment of haematemesis may be of interest.

\section{Gastritis and Haemorrhage}

In the majority of cases the bleeding occurs from minute erosions or small acute ulcers. These tend to heal rapidly; unless early gastroscopic examination is made, that is within about two to three days of the bleeding, the actual site of bleeding will escape notice. In about 50 per cent. of the gastritis and ' uncertain cause' cases, achlorhydria or atrophic gastritis is present. As previously stated (Tanner, 1949), we believe that in such cases minute gastric erosions may lead to ulceration of the submucosal vessels and on two occasions such an erosion was found overlying a prominent submucosal vessel (Fig. 9).

The question arises as to the correct procedure to be followed if at operation no gross lesion is found and a gastritic cause is consideredly likely, or confirmed by gastrotomy. This problem is not very infrequent, for some of the gastritis cases give an ulcer-like history of dyspepsia. We have usually claimed that if the gastric erosive or 
ulcerative lesion is so small as to elude detection by palpation or inspection of the serous surface, then it was unlikely to continue bleeding, and we contented ourselves with ligaturing the right and left gastric and right and left gastro-epiploic arteries. This has been successful hitherto, but a recent case gave us cause to change our method.

R.S., a Pole, aged 26, was admitted with a week's history of melaena and haematemesis without dyspepsia. Bleeding was repeated after admission and despite continuous slow transfusion the haemoglobin level remained at about 30 to 40 per cent. In view of the continued bleeding, following our routine in the last series, he was explored 48 hours after admission, but no lesion was found and vasoligation only performed. Despite this bleeding continued. Stored and later fresh blood was given, but despite this the haemoglobin remained low, and melaena continued. On the tenth day he had had 33 pints of blood and was still bleeding. Therefore again under local anaesthesia the abdomen was reopened and high partial gastrectomy was performed. The stomach showed only a few superficial erosions.

During the operation he had a further five pints of blood, and the next day he looked well and his haemoglobin was 96 per cent. He remained well until the fifth post-operative day when he had another haemorrhage which necessitated a further six pints slow transfusion.

Thereafter he did well and has remained well since discharge.

This case illustrates that gastrectomy is occasionally of value in these cases. One can only hope that by removing say, four-fifths of the gastric area, one diminishes the area left to bleed to one-fifth.

\section{Burns and Haematemesis}

A man aged 67 was admitted with severe burns. On the eighth day he developed severe haematemesis and melaena. As there was no history of dyspepsia a 'Curling's ulcer' was considered likely. He was treated conservatively but died despite repeated transfusion. At autopsy a large and chronic gastric ulcer was found.

\section{Pyloric Stenosis and Haematemesis}

We have found this a dangerous combination, the bleeding in such cases showing little tendency to cease spontaneously. The patients are often in very poor condition (one of our cases had tetany at the same time), and if not fit for gastrectomy, even a gastro-jejunostomy may be enough to turn the tide in the patient's favour, though if possible the bleeding vessel should be found and ligatured at the same time.

\section{Multiple Ulceration}

Multiple gastric or duodenal ulcers, or both, are quite common. On at least three occasions an ulcer which was believed to be the cause of the bleeding was found to have been a ' red herring,' a second unsuspected ulcer being the real cause in each case. On one of the occasions an unsuspected gastric ulcer was found in the gastrectomy specimen, but in two cases it was discovered at autopsy.

\section{Haemophilia and Haematemesis}

C.H., male aged 52. This patient first appeared with a haematemesis in 1945, when he was treated conservatively for a gastric ulcer which was diagnosed by gastroscopy. The bleeding ceased spontaneously although the patient was a known haemophiliac with a good family history and typical haemophilic joints. In 1949 he had another haematemesis, but this time it did not cease spontaneously, and partial gastrectomy was performed. (Three aneurysmal dilatations were found in the floor of the ulcer.) He had a small secondary haematemesis on the tenth day and sporadic bleeding from the wound continued for two weeks, but with daily small transfusions of fresh blood he made an excellent recovery.

\section{Concomitant Bleeding and Perforation of Ulcer}

Small haemorrhages at the time of perforation, or just prior to it are not very uncommon, and we have treated such cases by simple closure of the ulcer, using wide deep sutures through all the coats in addition to the Lembert stitches.

Haemorrhage occurring in the post-operative period after repair of a perforated ulcer presents a difficult problem. Out of eight such cases, four recovered on a conservative regime. The other four persisted with severe haemorrhage and all four were operated on. On one a yastrectomy was performed. The other three cases had giant ulcers and in view of their grave condition we contented ourselves with detaching the ulcer edges from liver and pancreas, trimming the edges and closing the stomach. All four recovered.

\section{High Blood Urea and Surgery}

There is an impression that a high blood urea contra-indicates surgical treatment. In so far as it is indicative of severe bleeding it may be regarded almost as an added incentive to surgery, though measures, especially restoration of blood volume, should be taken to reduce it. Eleven patients with blood ureas between 102 and I80 were operated upon and eight of these recovered. 


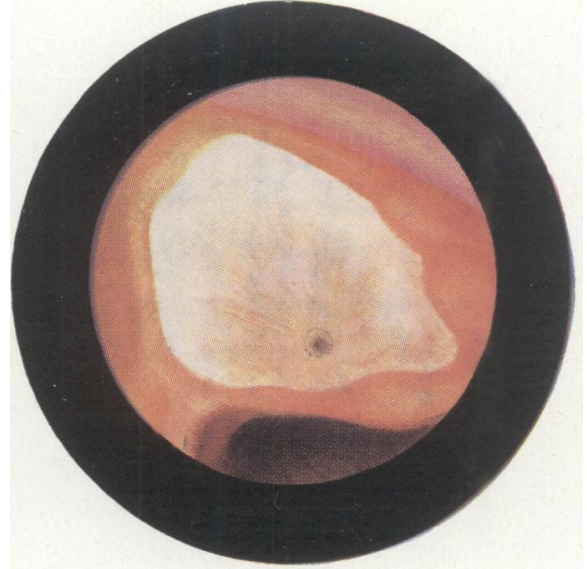

(a)

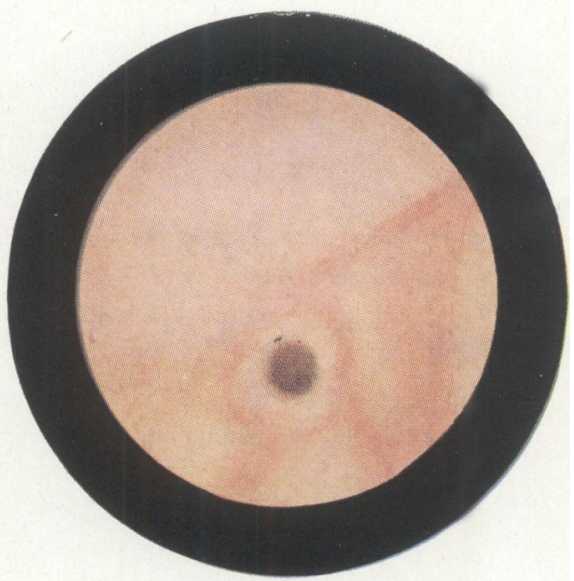

(b)

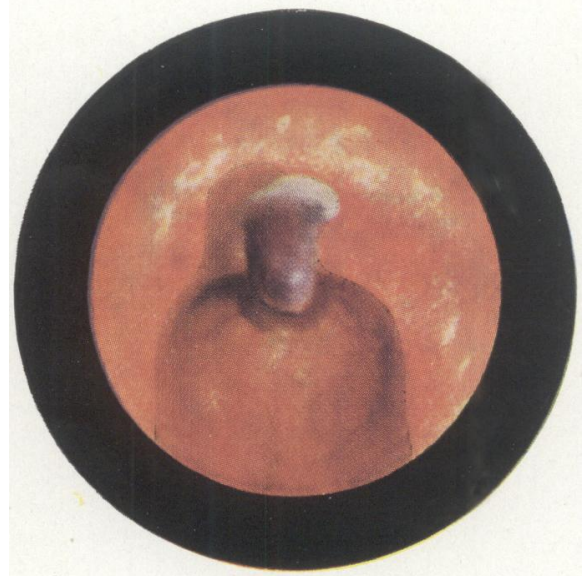

(c)

FIG. 10.-Three gastroscopic paintings after haematemesis. (a) shows a sealed vessel end in an ulcer crater. (b) shows blood clot filling the crater of an acute ulcer. Notice pallor of mucosa due to anaemia. (c) shows blood clot hanging out of a crater on the lesser curve.

\section{Haemorrhage and Pain}

We have found that pain usually disappears after a haemorrhage (Tanner, 1946). However, in some cases severe pain may persist, and this is often followed by further severe bleeding, particularly if the pain is in the back.

\section{The Place of Gastroscopy}

We find the gastroscope a most valuable aid in the diagnosis and treatment of these cases. Gastroscopy can be carried out at an early stage after bleeding has taken place. By its means lesions will be found which would be missed if one has to wait until the patient is fit for radiological examination, or indeed they may be too small and shallow for diagnosis by X-ray. By its use we have raised our ' certain diagnosis rate' after gastro-duodenal haemorrhage from 75 per cent. to over 90 per cent. of the cases.

When we are in doubt whether to operate we often perform gastroscopy, and our doubts are frequently resolved by the disclosure of an acute or chronic ulcer. Sometimes the sealed vessel end may be seen (Fig. IO); sometimes bleeding may still be taking place. If an atrophic gastric mucosa is seen it excludes duodenal ulceration.

Such information may indicate the correct line of treatment.

\section{The Operative Mortality in the Peptic Ulcer- Gastritis Group}

Altogether we have performed $\mathrm{I} 66$ operations in 748 incidents of bleeding. The oldest patient successfully operated on was aged $8 \mathrm{r}$. In the last or Finsterer series it will be seen that we have performed I IO operations on 183 cases with an operative mortality of 7 per cent., the youngest patient who died being aged 58 , the average age of fatal cases being 66 years. However, as we have tried to emphasize, it is not the operative mortality that interests us, it is the mortality of haematemesis and melaena. Which of these methods will enable the largest percentage of cases admitted with gastro-duodenal bleeding to return home ? If one operates late the operative mortality will be high, if one operates early it will be lower, but either will be correct if it produces the lowest overall mortality.

\section{Conclusion}

This investigation is still continuing. A bare inspection of our results in the peptic ulcergastritis group will suggest that our latest method of early and frequent operation is the most successful so far. This is even more emphasized when we compare the patients who are discharged 
after the two methods of treatment. Of those treated conservatively many will return with further ulcer complications, whereas most of those treated surgically are permanently cured of their ulcer.

On the other hand it must be admitted that there has been a definite steady fall in:mortality from gastro-duodenal bleeding of late years.

Finally we must reiterate that the cases are treated by a team, the members of which spend the greater part of their time diagnosing, nursing or treating peptic ulceration.

\section{BIBLIOGRAPHY}

AITKEN, R. S. (1934), Lancet, 1, 839.

AVERY-JONES, F. (1947), Brit. Med. Y., 2, 44 r.

BABEY, A. M., and HURST, A. F. (1936), Guy's Hospital Rep., $86,129$.

BENNETT, I., DOW, J., WRIGHT, S., and LANDER, L. (1938), Lancet, 2,651 .

BENNETT, T. I., DOW, J., and WRIGHT, S. (1942), Ibid., I, 55 I. BULMER, E. (1932), Ibid., 2, 720.

BURGER, G., and HARTFALL, S. J. (1934), Guy's Hosp. Rep., 84, 197.

CHIESMAN, W. E. (1932), Lancet, 2, 722.

COSTELLO, C. (1949), Ann. Surg., 129, 289.
FINSTERER, H. (1947), Wien. Med. Wschr., r, 3.

GORDON-TAYLOR, G. (1934), Proc. Roy. Soc. Med., 27, 1524 GORDON-TAYLOR, G. (1937), Brit. F. Surg., 25, 403.

GORDON-TAYLOR, G. (1945), Ibid., 33, 336.

HURST, A. F., STEWART, M. J. (1929), ' Gastric and Duodenal Ulcers,' Ox. Univ. Press, London.

LEWIS, I., quoted by GORDON-TAYLOR, G. (1946), Brit. 7 . Surg., 33, 336.

ROWNTREE, L. G., ZIMMERMAN, E. F., TODD, M. H., and AJAC, J. (1947), F. Am. Med. Ass., 135, 630 .

TANNER, N. C. (1946), Bristol Med. Chi. F., 63, 16.

TANNER, N. C. (1949), The Medical Press, 221, 3. 